\title{
O CAPITALISMO COMO RELIGIÃO
}

\author{
pressupostos de um diagnóstico benjaminiano
}

\author{
CAPITALISM AS RELIGION
}

assumptions of a Benjaminian diagnosis

Izabela Loner Santana ${ }^{1}$

(izabelalonersantana@gmail.com)

\begin{abstract}
RESUMO
Este artigo pretende analisar e compreender o texto/fragmento $O$ capitalismo como religião, escrito pelo filósofo Walter Benjamin em 1921. Esta análise é proposta de maneira a entender o imperativo que Benjamin coloca nas páginas de tal fragmento: deve-se ler o capitalismo como uma religião, o que, por sua vez, é explicitado durante o texto a partir da descrição dessa religião, de seu culto e da crítica benjaminiana à lógica capitalista, que não se restringe mais à esfera econômica ou à organização da sociedade na Modernidade, mas atravessa e perpassa todos os campos da vida humana. Em tais críticas, porém, pode-se observar o surgimento de uma das características mais marcantes do fragmento: apesar de ser um texto altamente anticapitalista e crítico, ele ainda está muito distante da teoria e da tradição marxistas, sendo muitas vezes, inclusive, crítico a essa tradição, pois é elaborado por um Benjamin que ainda se identifica mais com um socialismo romântico e libertário do que com um socialismo de orientação marxista.
\end{abstract}

Palavras-chave: Capitalismo. Walter Benjamin. Religião. Marxismo. Modernidade.

\begin{abstract}
The article aims to analyze and comprehend the text Capitalism as religion, written by Walter Benjamin in 1921. This analysis is proposed in order to understand the imperative Benjamin brings in the pages of such fragment: the duty to read capitalism as a religion. This, in turn, is done by describing this religion, its cult and understanding the Benjaminian criticism of its logic, which was no longer restricted to the economy or the organization of modern society, but crossed and surpassed all the scopes of human life. These criticisms allow the emergence of one of the most striking features of the fragment: despite being a highly anti-capitalist and critical text, it is very distant from Marxist theory and tradition, often being critical to it, since it is elaborated in a period in which Benjamin is closer to a romantic and libertarian socialism than to a socialism of Marxist orientation.
\end{abstract}

Keywords: Capitalism. Walter Benjamin. Religion. Marxism. Modernity.

\footnotetext{
${ }^{1}$ Bacharela em Ciências e Humanidades pela Universidade Federal do ABC (UFABC) e graduanda em Filosofia pela mesma instituição.

CV Lattes: http://lattes.cnpq.br/9830294071006375.
} 


\section{INTRODUZINDO A QUESTÃO}

O anticapitalismo de Walter Benjamin apresenta-se em seus escritos ainda antes de sua conversão ao marxismo, o que ocorre após sua leitura da obra História e consciência de classe, de Lukács, lançada em 1923. Tal anticapitalismo era orientado muitas vezes por um socialismo libertário, um anarcossindicalismo ou até mesmo por um socialismo romântico, e pode ser percebido em um fragmento de Benjamin intitulado $O$ capitalismo como religião, datado de 1921, que, além de se constituir de um socialismo romântico, constitui-se também por influências de Bloch, mais especificamente de seu livro, também de 1921, sobre o teólogo alemão Thomas Müntzer; e de Weber, mais diretamente em sua obra A ética protestante e o Espírito do capitalismo, de 1905 (BENJAMIN, 2013, p. 9).

Datado do início da década de 20, esse fragmento de Benjamin, apesar de não marxista, já é articulado a partir de uma análise materialista, concreta, da situação real do social, ao mesmo tempo em que faz uso da teologia enquanto estratégia de leitura e instrumento de crítica da Modernidade capitalista. Essa aglutinação entre um diagnóstico do concreto através da e com a teologia, relação que perpassa toda a sua obra até seus últimos escritos ${ }^{2}$, apresenta-se nesse texto no que pode ser percebido como uma recusa de reduzir o capitalismo a uma exploração meramente material. No imperativo de ler, buscar compreender e interpretar o capitalismo enquanto uma religião, já aparece, além da teologia, a necessidade de lê-lo enquanto um espírito que move e submete as pessoas em diversas frentes e em diversos campos da vida humana, esboçando-se a heterodoxia de Benjamin em sua crítica à Modernidade.

Já se pode, então, delimitar o objetivo deste artigo e falar como ele será articulado e desdobrado pelo texto: além de uma tentativa de interpretação e compreensão do escrito de Benjamin, buscar-se-á compreender, junto à tradição de comentários e interpretações, os diversos momentos e afirmações desse pequeno texto, principalmente o imperativo colocado por Benjamin: "O capitalismo deve ser visto como uma religião" (BENJAMIN, 2013, p. 21), procurando entender tal religião, seu culto e suas práticas a partir de uma perspectiva crítica, como propõe o filósofo.

\footnotetext{
${ }^{2}$ Para exemplificar tal afirmação, pode-se pensar nas teses Sobre o conceito de história de 1940, nas quais a relação entre um diagnóstico do concreto e do social, realizado então através de lentes marxistas, ainda se potencializa e se anima pela teologia, como bem ilustra o filósofo em sua Tese I. (BENJAMIN, 1985, p. 222)
} 
Em suma, a tentativa deste artigo é ouvir e recordar o caminho de crítica ao capitalismo deixado por Benjamin nesse fragmento, para que seja possível iluminar uma luta atual, potencializando a contemporaneidade contra o capitalismo - e ressoando o espírito das teses benjaminianas Sobre o conceito de história ${ }^{3}$, de 1940, que propõem uma experiência com o passado, com sua luta e seu sofrimento, de maneira tal que a luta presente seja possível: um salto dialético ao dito passado para dizer sobre o presente, ainda que o inimigo seja o mesmo. "A relação entre hoje e ontem não é unilateral: em um processo eminentemente dialético, o presente ilumina o passado, e o passado iluminado torna-se uma força no presente." (LÖWY, 2005, p. 61)

\section{O CAPITALISMO DEVE SER VISTO COMO UMA RELIGIÃO}

Walter Benjamin inicia seu fragmento afirmando que "o capitalismo deve ser visto como uma religião" (BENJAMIN, 2013, p. 21). Em verdade, tal afirmação coloca-se enquanto um imperativo, expresso em seu verbo. Já no início do fragmento, Benjamin impõe um dever. Tal afirmação precisa ser compreendida para além da metáfora, para além da analogia, para além da comparação entre a estrutura de uma religião, daquilo que se compreende modernamente enquanto religião, e o sistema capitalista. Na construção da frase, o "deve" mostra um imperativo, uma proposta de como olhar o capitalismo, uma maneira pela qual ele pode ser visto e compreendido.

O capitalismo e a religião, em suas convergências, afinidades ou apropriações - em outras palavras, em sua história comum -, já haviam sido abordados por Weber em sua obra sobre a ética protestante e como esta se relaciona com o capitalismo em sua emergência, além de seus artigos sobre sociologia da religião - o que inclusive consta no fragmento, especificamente no trecho em que Benjamin lista algumas de suas referências bibliográficas. Assim sendo, pode-se compreender que essa obra de Benjamin é influenciada por Weber, mas deve-se assumir, na companhia de Michael Löwy, que o filósofo vai muito além, transpassando e ultrapassando Weber, deslocando a discussão suscitada pelo sociólogo para o campo filosófico, além de não mais construir sua reflexão em torno de uma pseudoneutralidade, como

\footnotetext{
${ }^{3}$ BENJAMIN, Walter. Magia e técnica, arte e política: ensaios sobre literatura e história da cultura. Obras escolhidas, v. 1. 1 ed. Trad. Sergio Paulo Rouanet, 1985.
} 
no fazer sociológico, mas posicionando tal articulação, dando-lhe um caráter crítico, anticapitalista.

\begin{abstract}
O texto de Benjamin é obviamente inspirado na obra A ética protestante e o espírito do capitalismo de Max Weber; esse autor é citado duas vezes, primeiro no corpo do documento, e depois nos registros bibliográficos, nos quais é mencionada a edição de 1920 do Gesammelte Aufsätze sur Religionssoziologie, bem como o trabalho de Ernst Troeltsch, Die Soziallehren der Christlichen Kirchen und Gruppen, edição de 1912, que defende teses substancialmente idênticas às de Weber sobre a questão da origem do capitalismo. No entanto, como veremos, o argumento de Benjamin vai muito além de Weber e, acima de tudo, ele substitui sua abordagem "axiologicamente neutra" [Wertfrei] por uma acusação anticapitalista fulminante. (LÖWY, 2006, p. 204, tradução nossa) ${ }^{4}$
\end{abstract}

No corpo do fragmento, Benjamin aponta a diferença de sua reflexão acerca do relacionamento entre capitalismo e religião, contrapondo-a à reflexão sociológica elaborada por Weber. Nesse apontamento, Benjamin afirma pretender mostrar que o capitalismo pode se dar enquanto "um fenômeno essencialmente religioso", que se engaja em desempenhar o papel até então restrito às religiões, buscando respostas às aflições que até pouco, antes da Modernidade, direcionavam-se ao âmbito religioso - diferentemente de Weber, que compreendia o capitalismo enquanto algo condicionado pela religião.

\title{
3. A DESCRIÇÃO DO CULTO CAPITALISTA
}

Esta estrutura religiosa do capitalismo começa então a ser considerada por Benjamin. Para isso, ele aponta três principais traços, a saber: (1) o caráter cultural da religião capitalista; (2) a duração permanente de seu culto; e (3) o caráter culpabilizador desse culto.

Para definir o traço primeiro, é interessante salientar que a descrição da lógica capitalista que busca visá-lo enquanto uma estrutura religiosa é realizada pela descrição de seu culto, isto é, pela descrição de como se dão suas práticas, uma vez que é uma religião essencialmente

\footnotetext{
${ }^{4}$ «Le texte de Benjamin est, de toute évidence, inspiré par L'éthique protestante et l'esprit $d u$ capitalisme de Max Weber; cet auteur est deux fois cité, d'abord dans le corps du document, et ensuite dans les notices bibliographiques, où se trouve mentionnée l'édition de 1920 des Gesammelte Aufsätze sur Religionssoziologie, ainsi que l'ouvrage d'Ernst Troeltsch, Die Soziallehren der christlichen Kirchen und Gruppen, édition de 1912, qui défend, sur la question de l'origine du capitalisme, des thèses sensiblement identiques à celles de Weber. Cependant, comme nous verrons, l'argument de Benjamin va bien au-delà de Weber, et, surtout, il remplace sa démarche "axiologiquement neutre" (Wertfrei) par un fulminant réquisitoire anticapitaliste.»
} 
cultural, na qual "todas as coisas só adquirem significado na relação imediata com o culto; ele não possui uma dogmática, nenhuma teologia” (BENJAMIN, 2013, p. 21).

Essa religião não é transcendente, mas tem, em sua pragmática, em seus atos utilitários, em suas liturgias, ritos e culto, sua expressão religiosa. Isso torna possível a comparação que o autor realiza, no último parágrafo do texto, entre o capitalismo como religião e o paganismo original, uma vez que ambos não buscam a transcendência, mas limitam-se ao imediatamente prático: "Contribui para o conhecimento do capitalismo enquanto religião ter presente que o paganismo original certamente foi o primeiro a não conceber a religião como interesse 'moral', 'mais elevado', mas como interesse prático o mais imediato possível [...]” (BENJAMIN, 2013, p. 25).

Seguindo ainda essa comparação, Benjamin comenta o caráter da concepção que tanto o paganismo original quanto o capitalismo têm de seus adeptos. Ambos os fenômenos compreendem todos da comunidade enquanto parte de seu culto, enquanto "membro inquestionável", mesmo que este participe de outra crença, ou seja, sendo até mesmo irreligioso. No culto moderno capitalista, ou se cultua ou se cultua; não há alternativa, não há esperança ou escapatória. Todos são vistos enquanto parte integrante desse grande culto e movimento dinâmico que é o capitalismo. Isso implica a não necessidade de uma adesão a uma doutrina ou a um credo, até pelo motivo de tais não existirem. O que se exige é que se cultue, que se tenham as práticas sociais/culturais do capitalismo, que se jogue o jogo.

A impossibilidade de saída do culto relaciona-se diretamente com o segundo traço do capitalismo enquanto religião: a duração permanente de seu culto, a duração "sem trégua e sem piedade" de seu culto (BENJAMIN, 2013, p. 22). Se a Reforma Protestante, com o luteranismo e o calvinismo, buscou o fim dos dias festivos com o argumento contra a ociosidade, ela instaura a saturação dos dias, transformando todos eles em dias festivos, fundando um calendário sem dias normais, mas com festividades e culto constantes.

Apesar de descrever o capitalismo como uma religião pelo caráter de seu culto, Benjamin em momento algum descreve o culto, os ritos, as práticas culturais, mas aponta que nele há adorador, adoração e divindades às quais tal culto é prestado. Segundo Löwy (2006), isso pode ser pensado juntamente a uma comparação, proposta por Benjamin, entre as cédulas bancárias dos diferentes Estados e os santos das diversas religiões (BENJAMIN, 2013, p. 23). Assim, tem-se na cédula, em uma das diversas formas de expressão da riqueza, o dinheiro, o objeto de adoração próprio do capitalismo como religião, algo similar à referência prestada aos santos das diversas religiões. 
Ao fim do texto, como já citado acima, há anotações bibliográficas; entre elas, Benjamin indica a obra Convocação ao socialismo [Aufruf zum Sozialismus], de Gustav Landauer - mais especificamente a página 144 da obra, a qual traz o seguinte dito:

Fritz Mauthner (Wörterbuch der Philosophie) mostrou que a palavra "deus" [Gott] é originariamente idêntica a "ídolo" [Götze], e que as duas querem dizer "o fundido" [Gegossene]. Deus é um artefato feito pelos humanos, que ganha uma vida, atrai para si as vidas dos humanos e finalmente torna-se mais poderoso que a humanidade. O único fundido, o único ídolo, o único Deus a que os humanos deram vida é o dinheiro [Geld]. O dinheiro é artificial e é vivo, o dinheiro produz dinheiro e mais dinheiro, o dinheiro tem todo o poder do mundo. (LANDAUER, 1919, p. 144, tradução nossa) ${ }^{5}$

Curioso notar aqui, mais uma vez, a distância de Benjamin, por ora, em relação à teoria e à tradição marxistas, além de sua proximidade para com o socialismo romântico e libertário, o que pode ser visto pelo uso da noção de dinheiro, e não de uma noção mais ampla como a de capital. Se nesse escrito o dinheiro pode ser compreendido enquanto o ídolo a ser cultuado, em uma leitura marxista essa compreensão poderia ser deslocada ao capital, uma vez que o dinheiro, o papel-moeda, é apenas uma das diversas manifestações do capital, assim como o é

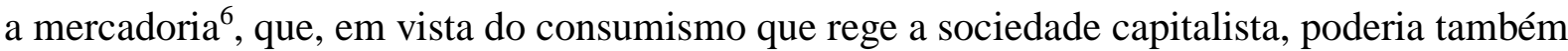
ser considerada um ídolo.

Do ponto de vista marxista, o dinheiro seria apenas uma das manifestações e não a mais importante - do capital, mas Benjamin estava muito mais próximo, em 1921, do socialismo romântico e libertário de um Gustav Landauer - ou de um Georges Sorel - do que do de Karl Marx e Friedrich Engels. Foi somente mais tarde, nas Passagens, que ele foi inspirado por Marx a criticar o culto fetichista da mercadoria, e a analisar passagens parisienses como "templos de capital mercantil". (LÖWY, 2006, p. 207, tradução nossa) ${ }^{7}$

\footnotetext{
5 «Fritz Mauthner (Wörterbuch der Philosophie) a montré que le mot 'Dieu' (Gott) est originairement identique avec 'Idole' (Götze), et que les deux veulent dire 'le fondu' [ou 'le coulé'] (Gegossene). Dieu est un artefact fait par les humains, qui gagne une vie, attire vers lui les vies des humains, et finalement devient plus puissant que l'humanité. Le seul coulé (Gegossene), le seul idole (Götze), le seul Dieu (Gott), auquel les êtres humains ont donné vie, c'est l'argent (Geld). L'argent est artificiel et il est vivant, l'argent produit de l'argent et encore de l'argent, l'argent a toute la puissance du monde.»

${ }^{6}$ Cf. MARX, Karl. O Capital: crítica da economia política - livro 1. Trad. Rubens Enderle. São Paulo: Boitempo, 2013.

7 «D'un point de vue marxiste, l'argent ne serait qu'une des manifestations - et pas la plus importante - du capital, mais Benjamin était beaucoup plus proche, en 1921, du socialisme romantique et libertaire d'un Gustav Landauer - ou d'un Georges Sorel - que de Karl Marx et Friedrich Engels. Ce n'est que plus tard, dans le Passagenwerk, qu'il va s'inspirer de Marx pour critiquer le culte fétichiste de la marchandise, et analyser les passages parisiens comme 'temples du capital marchand'.»
} 
Outro traço do culto da religião capitalista é seu caráter culpabilizador. Diferente dos cultos de outras religiões que pregam e buscam a expiação, a purificação dos pecados e dos erros, o capitalismo como religião é culpabilizador, age sobre a consciência por meio de uma culpa constante e inescapável, e não de modo a exigir sua purificação, mas de forma a expandila até o próprio Deus, tornando-a assim universal. O objetivo da culpabilização é o próprio movimento de culpabilização, o martelar da culpa, o estado de culpa e desespero universal. Sugerir que até Deus se submeterá a essa culpa é sugerir de forma implícita que, com o novo deus dinheiro, Deus é deslocado de seu lugar primeiro de todo-poderoso e passa a ser mais um assujeitado do deus dinheiro - “A transcendência de Deus ruiu” (BENJAMIN, 2013, p. 22).

Benjamin ainda aponta para a "ambiguidade demoníaca", para o duplo sentido da palavra culpa [Schuld], que, na tradução para o português, pode ser vertida tanto por culpa como por dívida, débito (BENJAMIN, 2013, p. 23), tomando proporção e significação enormes em um contexto no qual o capitalismo não só está inserido, mas é constituinte, estruturante. Assim, a própria etimologia da palavra suscita uma hipótese do caráter da culpa frequentemente citada por Benjamin, a saber, que o caráter da culpa dentro do capitalismo visto como uma religião relaciona-se com a dívida, o débito.

\section{OS PROFETAS DO CULTO MODERNO}

Benjamin, para descrever e criticar a religião e seu caráter culpabilizador, evoca três grandes pensadores, os quais Agamben chama de profetas da Modernidade, para realizar breves críticas em torno de suas reflexões teóricas e da relação destas com a Modernidade:

Precisamente porque tende com todas as suas forças não à redenção, mas à culpa, não à esperança, mas ao desespero, o capitalismo como religião não tem em vista a transformação do mundo, mas a sua destruição. E o seu domínio é, em nosso tempo, tão total que até os três grandes profetas da modernidade (Nietzsche, Marx e Freud) conspiram, segundo Benjamin, com ele, são solidários, de algum modo, com a religião do desespero. (AGAMBEN, 2003)

Assim, cabe tratar das reflexões de Benjamin acerca desses intelectuais e compreender a crítica realizada a eles, uma vez que são, segundo Agamben, os grandes profetas da religião capitalista. 


\subsection{Nietzsche, o primeiro profeta}

As considerações benjaminianas acerca do pensamento de Nietzsche têm duas frentes: por um lado, Benjamin discorda dele, negando a morte de Deus, pois coloca que este apenas foi incluído no destino humano; por outro lado, traz o Übermensch de Nietzsche enquanto éthos do ser humano em sua passagem pela "casa do desespero" causado pela existência no capitalismo - "esse ser humano é o Übermensch, o primeiro que começa a cumprir conscientemente a religião capitalista." (BENJAMIN, 2013, p. 22). Assim, Benjamin tem na filosofia nietzschiana o lugar em que o pensamento religioso capitalista "ganha expressão grandiosa", uma vez que ela propõe, com o Übermensch, a "intensificação constante" que prega a lógica e o culto capitalistas, colocando o ser humano histórico como aquele que cresceu até alcançar os céus, o limite, através de sua "humanidade intensificada" - o que, olhado de uma perspectiva religiosa, nada mais é do que a culpabilização.

Löwy (2006) levanta uma hipótese do motivo pelo qual Benjamin invoca Nietzsche ao falar do desespero humano, pois, apesar de não trazer diretamente a questão do capitalismo em sua obra, Nietzsche aponta para um destino fatalista, para um fatalismo pessimista, algo que já em Weber era descrito como um dos traços mais marcantes do capitalismo: ser inescapável, destino da era moderna:

Este é o significado das últimas páginas da Ética protestante, na qual Weber, com o fatalismo pessimista, afirma que o capitalismo moderno "determina, com força irresistível, o estilo de vida de todos os indivíduos nascidos nesse mecanismo - e não apenas aqueles diretamente relacionados com a aquisição econômica". (LÖWY, 2006, p. 211, tradução nossa) ${ }^{8}$

\subsection{Freud, o segundo profeta}

As considerações benjaminianas sobre a teoria de Freud concentram-se no seguinte trecho: "A teoria freudiana também faz parte do império sacerdotal desse culto. Ela foi concebida em moldes totalmente capitalistas. A partir de uma analogia muito profunda ainda a ser esclarecida, aquilo que foi reprimido - a representação pecaminosa - é o capital que rende juros para o inferno do inconsciente" (BENJAMIN, 2013, p. 22).

\footnotetext{
${ }^{8}$ «C'est le sens des dernières pages de L'éthique protestante, où Weber, constate, avec un fatalisme pessimiste, que le capitalisme moderne 'détermine, avec une force irrésistible, le style de vie de l'ensemble des individus nés dans ce mécanisme - et pas seulement de ceux que concerne directement l'acquisition économique'.»
} 
O próprio autor já aponta para a profundidade e a falta de esclarecimento da analogia que propõe, mas, mesmo assim, não deixa de propô-la. Ele afirma que a própria concepção da teoria freudiana se dá nos moldes capitalistas; logo em seguida, constata que o reprimido - ou seja, aquilo que fora voluntariamente inibido, arrancado do consciente por uma ação psíquica de supressão consciente de uma ideia, afeto, lembrança desagradável (ROUDINESCO, 1997, p. 659) - é o capital que rende juros.

Uma tentativa de compreender a analogia de Benjamin, ou talvez um modo de jogar luz a seus ditos, pode partir de um ponto de vista psicanalítico. Na psicanálise, principalmente a de orientação freudiana, aquilo que é reprimido continua a retornar de outras formas, em outras intensidades, permanecendo um incômodo, gerando um constante mal-estar que muitas vezes se desloca do conteúdo que lhe deu origem. Assim, a lógica capitalista, por ser desagradável, é reprimida, reformulada de maneira a não ser mais consciente, não mais ser explícita, passando a atuar gerando mal-estar, sempre rendendo juros e culpa ao inferno que se torna o inconsciente.

Benjamin talvez tente mostrar como o capitalismo entraria à força nos indivíduos, obrigando-os a participar do culto, sem que eles possam escolher aderir ou não, imprimindolhes culpa e, assim, angústia:

\begin{abstract}
As preocupações: uma doença do espírito própria da época capitalista. Situação sem saída de cunho espiritual (não material) em forma de pauperismo, vadiagem, mendicância, monaquismo. Uma condição tão sem saída e culpabilizadora. As "preocupações" são indicativas dessa consciência de culpa provocada pela situação sem saída. "Preocupações" surgem da angústia provocada pela situação sem saída de cunho comunitário, não de cunho material-individual. (BENJAMIN, 2013, p. 24)
\end{abstract}

\title{
4.3 Marx, o terceiro profeta
}

Aos que se acostumaram com o Benjamin marxista, apesar de heterodoxo, podem estranhar o teor desta crítica, mas deve-se lembrar que o texto em questão foi escrito antes do encontro de Benjamin com o marxismo, como já citado anteriormente. Assim, a distância em relação à teoria marxista permite que o filósofo empreenda uma crítica ao projeto socialista pensado por Marx.

Benjamin, em proximidade com as ideias de Landauer, provavelmente partilha e imprime sua crítica ao marxismo. Tal crítica baseia-se na ideia de que o marxismo nada mais estaria fazendo do que estabelecer uma espécie de Kapitalsozialismus. Assim, o capitalismo apenas se converteria em socialismo, sem um rompimento ou mudança 
de lógica; em outras palavras, o socialismo desenvolver-se-ia a partir do capitalismo, o modo de produção socialista floresceria a partir do capitalismo, a partir de uma centralização do crédito e da produção.

Assim, para Benjamin, o marxismo ainda se reduziria às categorias da religião capitalista, não sendo uma saída efetiva de seu desespero nem de seu culto: “[...] o capitalismo impertinente se converte em socialismo com juros e juros sobre juros, que, como tais, são em função da culpa (ver ambiguidade demoníaca desse conceito)" (BENJAMIN, 2013, p. 23). O socialismo marxista, continuando em uma mesma esteira, ainda participaria de um culto culpabilizador, ainda imputaria a seus fiéis culpa.

\section{CONSIDERAÇÕES FINAIS}

Por fim, após listar e explicitar os três principais traços do capitalismo visto como religião, Benjamin aponta algo que denominou como o "aspecto inaudito do capitalismo": sendo uma religião, o capitalismo não mais busca uma reforma das pessoas ou do ser, mas impõe-lhes o esfacelamento.

A lógica capitalista expande o desespero até a camada religiosa do social, mostrando como tal lógica absorve e coopta todas as esferas da vida na Modernidade, não se restringindo à econômica. Assim, nem mais a religiosidade pode oferecer salvação; ela se torna estéril ao ser parasitada pelo capitalismo: "Ela [a religião capitalista] é a expansão do desespero ao estado religioso universal, do qual se esperaria a salvação" (BENJAMIN, 2013, p. 22).

Dessa forma, Benjamin pode retomar a tese de Weber de que o cristianismo (forma religiosa quase hegemônica da Modernidade ocidental) favoreceu o surgimento do capitalismo, uma vez que, após sua proposta e exposição no fragmento, fica claro que em verdade o cristianismo, a religiosidade dominante, fora transformada, absorvida, cooptada pelo capitalismo - o que talvez mostre o motivo pelo qual o capitalismo possa ser visto também como uma religião. 


\section{REFERÊNCIAS}

AGAMBEN, Giorgio. Walter Benjamin e o capitalismo como religião. Disponível em: $<\underline{\text { https://dialogosdosul.operamundi.uol.com.br/economia/50226/walter-benjamin-e-o- }}$ capitalismo-como-religiao>. 2003. Acesso em 1 de fevereiro de 2019.

BENJAMIN, Walter. Magia e técnica, arte e política: Ensaios sobre literatura e história da cultura. Obras escolhidas, v. 1.1 ed. Trad. Sergio Paulo Rouanet. São Paulo: Brasiliense, 1985.

. O capitalismo como religião. Org. Michael Löwy. Trad. Nélio Schneider. 1 ed. São Paulo: Boitempo, 2013.

LANDAUER, Gustav. Aufruf zum Sozialismus. Berlin: Paul Cassirer, 1919.

LÖWY, Michael. Alarme de incêndio: uma leitura das teses "Sobre o conceito de história”. São Paulo: Boitempo, 2005.

. Le capitalisme comme religion: Walter Benjamin et Max Weber. Raisons Politiques, 2006/3, n. 23, p. 203-219. Disponível em < https://www.cairn.info/revue-raisonspolitiques-2006-3-page-203.htm>. Acesso em 20 de julho de 2018.

LUKÁCS, György. História e consciência de classe. Trad. Rodnei Nascimento, São Paulo: Martins Fontes, 2003.

MARX, Karl. O Capital: crítica da economia política - livro 1. Trad. Rubens Enderle. São Paulo: Boitempo, 2013.

ROUDINESCO, Elisabeth. Dicionário de psicanálise. Trad. Vera Ribeiro. Rio de Janeiro: Jorge Zahar, 1997.

WEBER, Max. A ética protestante e o Espírito do capitalismo. Trad. José Marcos Mariani de Macedo. São Paulo: Companhia das Letras, 2004. 